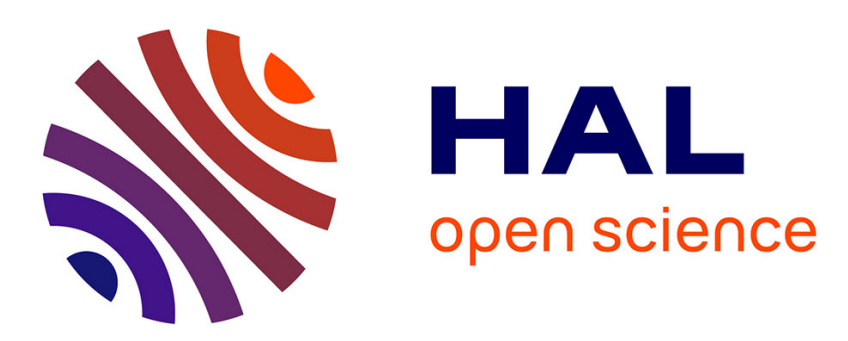

\title{
Quantification of monosaccharide anhydrides by gas chromatography/mass spectrometry in lichen samples
}

Charles-Enzo Dauphin, Amandine Durand, Kévin Lubonis, Henri Wortham, Julien Dron

\section{- To cite this version:}

Charles-Enzo Dauphin, Amandine Durand, Kévin Lubonis, Henri Wortham, Julien Dron. Quantification of monosaccharide anhydrides by gas chromatography/mass spectrometry in lichen samples. Journal of Chromatography A, 2020, 1612, pp.460675. 10.1016/j.chroma.2019.460675 . hal-02943004

\author{
HAL Id: hal-02943004 \\ https://hal.science/hal-02943004
}

Submitted on 29 Sep 2020

HAL is a multi-disciplinary open access archive for the deposit and dissemination of scientific research documents, whether they are published or not. The documents may come from teaching and research institutions in France or abroad, or from public or private research centers.
L'archive ouverte pluridisciplinaire HAL, est destinée au dépôt et à la diffusion de documents scientifiques de niveau recherche, publiés ou non, émanant des établissements d'enseignement et de recherche français ou étrangers, des laboratoires publics ou privés. 
Short communication

\title{
Quantification of monosaccharide anhydrides by gas chromatography/mass spectrometry in lichen samples
}

\author{
Charles-Enzo Dauphin ${ }^{\mathrm{a}}$, Amandine Durand ${ }^{\mathrm{b}}$, Kévin Lubonis ${ }^{\mathrm{a}}$, Henri Wortham ${ }^{\mathrm{b}}$, Julien Dron ${ }^{\mathrm{a}, *}$ \\ ${ }^{a}$ Institut Ecocitoyen pour la Connaissance des Pollutions, Fos-sur-Mer, France \\ b Aix Marseille Univ, CNRS, LCE, Marseille, France
}

\section{A R T I C L E IN F O}

\section{Article history:}

Received 5 July 2019

Received in revised form 8 October 2019

Accepted 3 November 2019

Available online $\mathrm{xxx}$

Keywords:

Levoglucosan

Monosaccharide anhydrides

Biomass burning tracer

Lichen

Atmospheric bioindicator

\begin{abstract}
A B S T R A C T
Lichens are effective atmospheric bioindicators, and the bioaccumulation of pollutants is frequently measured in their tissues to assess contamination levels. Even though monosaccharide anhydrides are not directly considered as contaminants, Levoglucosan is a common tracer of biomass burning in atmospheric samples and measuring their accumulation in lichens could help to evaluate the main atmospheric pollution sources on a spatially resolved scale depending on the size of the sampling grid. In this work, a realiable analytical method to determine monosaccharide anhydrides in liches was developed. It is based on ASE extraction, solid phase extraction to clean the sample, and silylation derivatization before GC/MS analysis. The reliability and detection limits of the method were suited to the analysis of lichen samples, and additional quality tests achieved the validation of the method with lichen test matrix. Finally field samples were quantified and the results obtained were consistent with atmospheric levels.
\end{abstract}

(C) 2019 .

\section{Introduction}

Lichen are used as atmospheric pollution bioindicators since decades, and demonstrated bioaccumulation features in bioaccumulation of metal elements, polycyclic aromatic hydrocarbons, dioxins and furans and other organics $[1,14,17]$. More recently, some works showed promising perspectives in performing source apportionment studies from lichen chemical content $[3,17]$. In this context, the potentially high spatial resolution and the long integration time offered by lichen would be very complementary to the usual active sampling methods which provide source apportionment results at a high frequency but limited to very few sampling sites simultaneously [5, 6 , 20].

Specific markers are often determined in ambient air to discriminate atmospheric pollution sources (fossil fuel combustion, industrial processes, biomass burning, secondary aerosols). As combustion products of cellulose, monosaccharide anhydrides are reliable indicators of biomass burning emissions [19], and they are generally determined by liquid or gas chromatography associated to mass spectrometry, e.g. LC/MS or GC/MS [22]. There are numerous methods reported for atmospheric particulate matter, ice, soil and sediment $[8,12,15$, $21,22]$. To our knowledge, there is only one reference to levoglucosan and congeners in a biological matrix [13], but did not provide quantitative results.

\footnotetext{
* Corresponding author.

Email address: julien.dron@institut-ecocitoyen.fr (J. Dron)
}

Levoglucosan and its congeners have only a few days lifetime in the atmosphere according to reaction with $\mathrm{OH}$ radicals, but may remain for years in less exposed matrices such as soils, sediments and ice [11, 21]. Also, PAH, PCDDF and PCB for example, which have comparable lifetimes in the atmosphere, soils and sediments, are well retrieved in lichen with an integration time estimated to several months [17]. As a result, it may be expected that monosaccharide anhydrides remain for months in lichen.

In order to enhance the source apportionment studies using lichen as atmospheric bioaccumulators, we developed an analytical method to determine levoglucosan, mannosan and galactosan in lichen samples. To our knowledge, this is the first report of quantitative analytical method for the determination of monosaccharide anhydrides in a biological sample. The sample preparation, based on solvent extraction and solid phase clean-up, and the GC/MS analysis were thoroughly examined and optimized.

\section{Materials and methods}

\subsection{Field samples collection and preparation}

The field samples were collected in urban background sites (e.g. parcs or gardens), in Vitrolles, Marseille and Aix-en-Provence (South of France) city centers, on February 14 and 15, 2017. Marseille is located by the Mediterranean Sea and is the largest city in the area (pop. 860 000), before Aix-en-Provence (pop. 140 000) which is located $20 \mathrm{~km}$ inland. About $15 \mathrm{~km}$ away, Vitrolles (pop. 34000 ) is a more industrial town located a few $\mathrm{km}$ from an international airport 
Table 1

Recoveries (\%) of levoglucosan (levo), mannosan, galactosan measured according to the solvent nature and the ratio of acetone volume to analyte load. Values in brackets were obtained for the internal standard levoglucosan-d7 (levo-d7) during the experiments with acetone.

\begin{tabular}{lllll}
\hline Solvent & $\begin{array}{l}\text { Analyte load } \\
(\boldsymbol{\mu g})\end{array}$ & \multicolumn{2}{l}{ Recoveries $(\%)$} & \\
\hline & & $\begin{array}{l}\text { levo (levo- } \\
\mathbf{d} 7)\end{array}$ & mannosan & galactosan \\
& & 0 & 0 & 100 \\
Acetonitrile & 50 & & & \\
$\quad(6 \mathrm{~mL})$ & & 0 & 0 & 0 \\
Methanol $(6 \mathrm{~mL})$ & 50 & $\operatorname{tr}$ & 0 & $\operatorname{tr}$ \\
Ethanol $(6 \mathrm{~mL})$ & 50 & $83(85)$ & 76 & 92 \\
Acetone $(6 \mathrm{~mL})$ & 50 & $100(113)$ & 94 & 104 \\
Acetone $(6 \mathrm{~mL})$ & 200 & $89(89)$ & 73 & 89 \\
Acetone $(12 \mathrm{~mL})$ & 50 & $86(89)$ & 77 & 85 \\
Acetone $(18 \mathrm{~mL})$ & 50 & & & \\
\hline
\end{tabular}

a petrochemical complex. Additional samples from several spots were collected and brought together to constitute a large lichen test sample.

The sampling was carried out according to a procedure described in detail in a previous work [17]. Briefly, about $10 \mathrm{~g}$ wet weight (ww) whole Xanthoria parietina thalli were collected, using ceramic knives, on 5 to 10 tree trunks located inside a $200 \mathrm{~m}^{2}$ area. They were placed immediately in a Nalgene ${ }^{\circledR}$ flask and stored at $4{ }^{\circ} \mathrm{C}$ in the dark. Within $24 \mathrm{~h}$, they were sorted with non-metallic tools (ceramic and antistatic PS) to remove remaining dust, bark and unwanted species. They were freeze-dried and grounded in a ball mill equipped with $\mathrm{ZrO}_{2}$ beads and capsules, giving a fine and homogeneous powder and finally stored at $-40^{\circ} \mathrm{C}$.

\subsection{Chemicals and standards solutions}

Standard solutions $\left(1 \mathrm{~g} \mathrm{~L}^{-1}\right)$ of levoglucosan (1,6-anhydro- $\beta$-D-glucopyranose, Sigma-Aldrich), galactosan (1,6-anhydro- $\beta$-D-galactopyranose, Santa Cruz Biotechnology), mannosan (1,6-anhydro- $\beta$-D-mannopyranose, Santa Cruz Biotechnology) and levoglucosan-d7 (1,6-anhydro- $\beta$-D-glucopyranose d7, Cambridge Isotopes Laboratories) were individually prepared in acetonitrile. A concentrated mother mix was obtained by dissolving them into dichloromethane to reach $5 \mathrm{mg} \mathrm{L}^{-1}$ for each compound. Solvents used (acetonitrile, dichloromethane, hexane and acetone) were all analytical grade (Sigma-Aldrich).
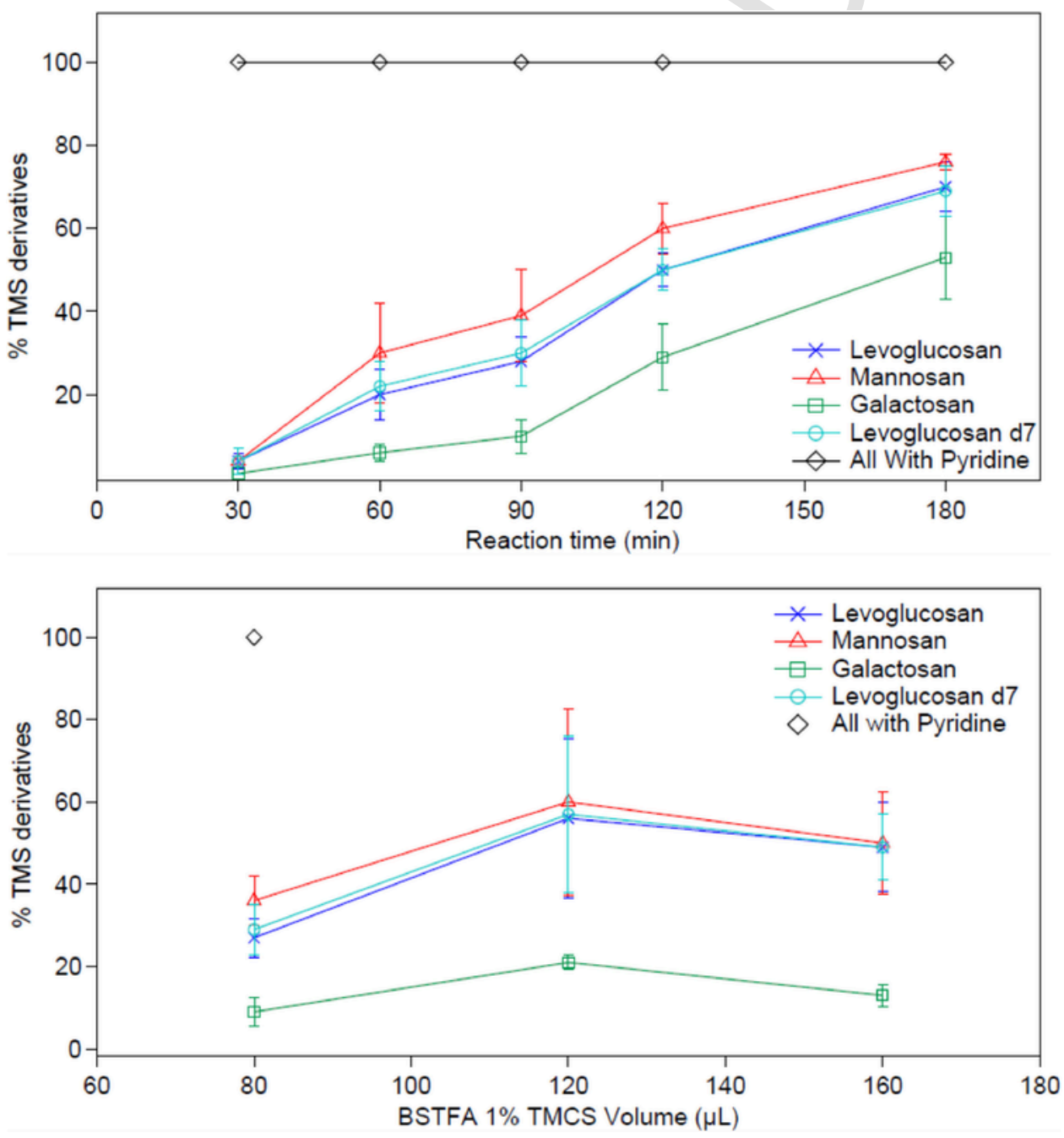

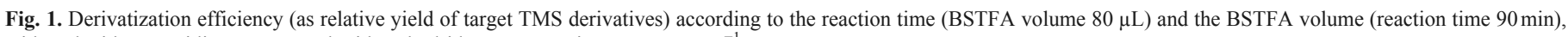
with and without pyridine. Monosaccharide anhydrides concentrations were $5 \mathrm{mg} \mathrm{L}^{-1}$. 
Table 2

LOD and LOQ of levoglucosan - mannosan - galactosan.

\begin{tabular}{llll}
\hline & LOD $\left(\mathrm{mg} \mathrm{L}^{-1}\right)$ & LOQ $\left(\mathrm{mg} \mathrm{L}^{-1}\right)$ & Quantifying Ion \\
\hline Levoglucosan & 0.08 & 0.24 & 204 \\
Mannosan & 0.02 & 0.06 & 217 \\
Galactosan & 0.04 & 0.12 & 217 \\
\hline
\end{tabular}

\subsection{Sample extraction, cleanup and derivatization}

\subsubsection{Extraction of monosaccharide anhydrides from the lichen matrix}

Approximately $0.5 \mathrm{~g}$ of lichen powder were precisely weighted and spiked with $1 \mu \mathrm{g}$ of levoglucosan-d7 as an internal standard and introduced in a $66 \mathrm{~mL}$ stainless-steel cell.

Accelerated Solvent Extraction was carried out with dichloromethane using an ASE 350 system (Dionex) at $100^{\circ} \mathrm{C}$ and 100 bars, according to the usual conditions defined by the manufacturer ( 2 cycles of $5 \mathrm{~min}$ ). Dichloromethane was chosen because it was well adapted to further SPE extraction purpose. The flush volume amounted to $60 \%$ of the extraction cell volume and the extract was purged from the cell using pressurized nitrogen for $100 \mathrm{~s}$. The extract was concentrated under a gentle $\mathrm{N}_{2}$ stream at $40^{\circ} \mathrm{C}$ (TurboVap II, Biotage) down to approximately $10 \mathrm{~mL}$. The number of ASE extraction cycles was optimized, and its efficiency was compared with ultrasonic extraction.

Ultrasonic extraction was performed with $0.5 \mathrm{~g}$ of lichen spiked with levoglucosan-d7 in $10 \mathrm{~mL}$ of dichloromethane. The extraction time was set to $30 \mathrm{~min}$ and the supernatant was decanted for $3 \mathrm{~h}$. A longer extraction time would no longer be advantageous compared to ASE conditions, and heating could not be considered according to the high volatility of dichloromethane.

The extract was finally filtered through a $0.45 \mu \mathrm{m}$ PTFE syringe filter (Sigma-Aldrich).

\subsubsection{Solid phase purification}

The filtered extracts were then purified by Solid Phase Extraction (SPE), on silica SPE cartridges (Supelco Discovery DSC-Si, $6 \mathrm{~mL}$, $1 \mathrm{~g}$, Sigma-Aldrich). The cartridge sorbent was initially conditioned with $6 \mathrm{~mL}$ hexane and $6 \mathrm{~mL}$ dichloromethane. The extract was slowly loaded and the cartridge was then rinsed with $6 \mathrm{~mL}$ hexane followed by $6 \mathrm{~mL}$ dichloromethane. Eventually, the targeted monosaccharide anhydrides were eluted drop by drop with $6 \mathrm{~mL}$ acetone. The extract was concentrated under a gentle stream of $\mathrm{N} 2$ and adjusted to a volume of $0.5 \mathrm{~mL}$ with acetonitrile. The samples were finally filtered again through a $0.45 \mu \mathrm{m}$ PTFE syringe filter.

The SPE purification was the key step in the sample preparation. Silica and Florisil cartridges (Supelclean ENVI, $6 \mathrm{~mL}, 1 \mathrm{~g}$, Sigma-Aldrich), as well as several eluting solvents were tested. Finally,
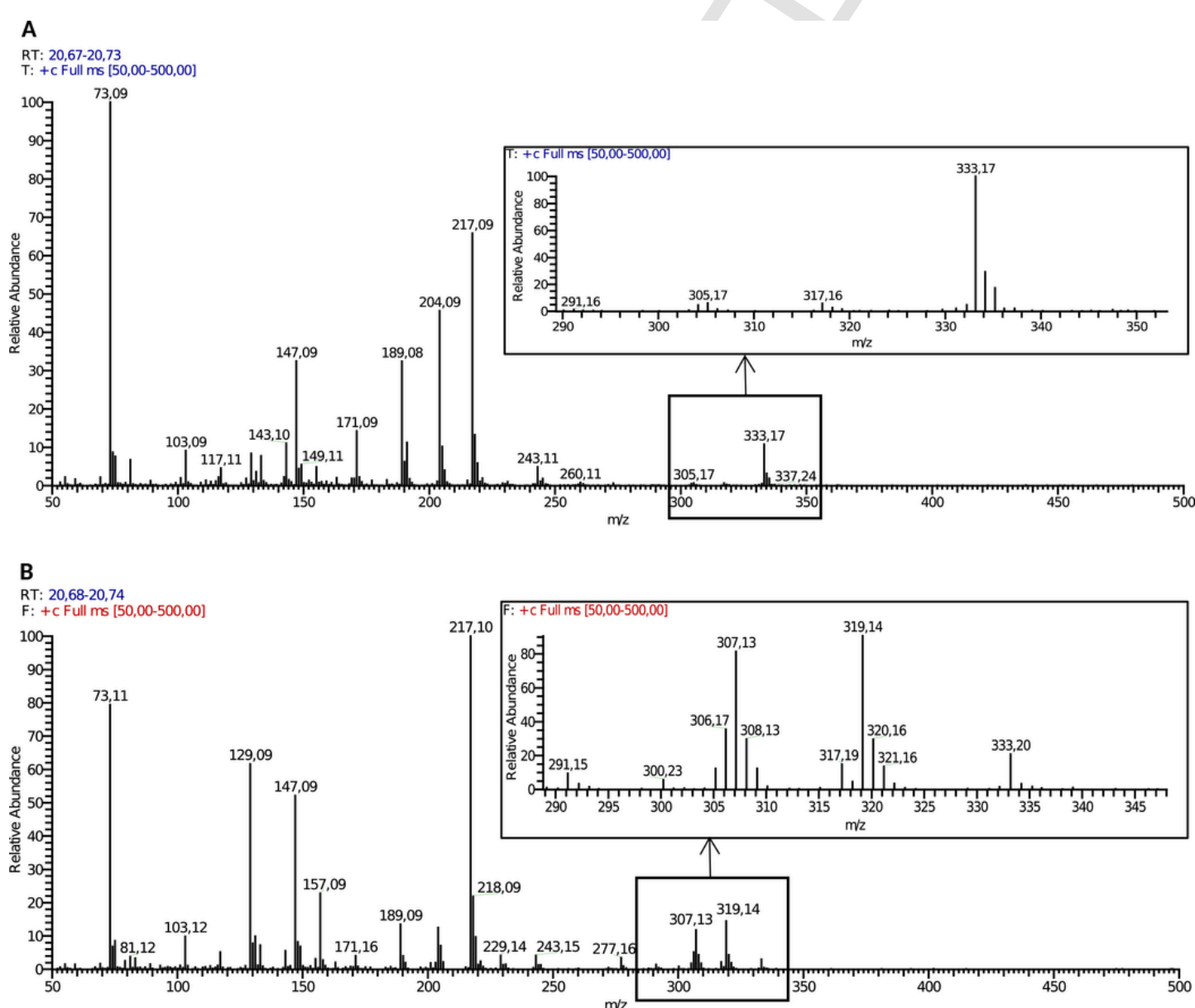

Fig. 2. MS spectrum of levoglucosan in a standard solution (A) and MS spectrum of levoglucosan co-eluting with a sugar alcohol compound in a lichen extract (B). 

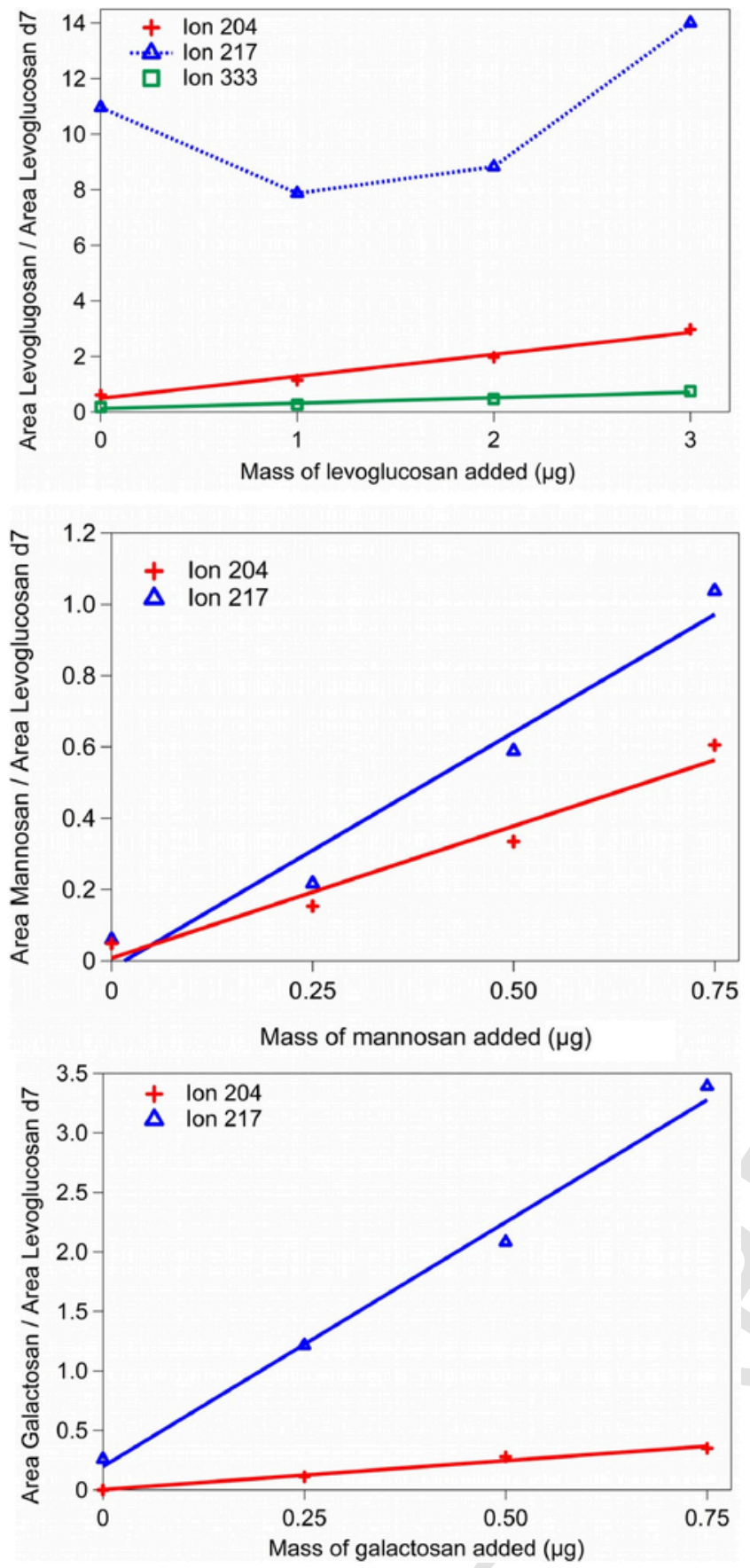

Fig. 3. Results of the standard addition method of levoglucosan, mannosan and galactosan in the lichen test matrix.

solvent volume and the sample quantity were optimized with the best cartridge-solvent association using the lichen test sample.

\subsubsection{Derivatization}

The monosaccharide anhydrides were derivatized by silylation in order to perform the GC-MS analysis of their trimethylsilyl (TMS) derivatives. In this objective, $80 \mu \mathrm{L}$ of BSTFA (N,O-Bis(trimethylsilyl)trifluoroacetamide) $+1 \% \mathrm{TMCS}$ (trimethylchlorosilane) (Sigma-Aldrich) and $80 \mu \mathrm{L}$ of pyridine (Sigma-Aldrich) as a catalyst were added to a $40 \mu \mathrm{L}$ aliquot of the final extract. The reaction was carried out at $70^{\circ} \mathrm{C}$ for $90 \mathrm{~min}$, and the sample was analyzed

within

$24 \mathrm{~h}$.

The reaction time and reagent quantity were optimized and the use of the pyridine as catalyst was evaluated.

\subsection{GC-MS conditions}

The GC-MS conditions, derived from previous works carried out on atmospheric particulate matter samples, are reported by El Haddad et al. [4, 5] and Sylvestre [20]. The analysis was done using a Trace GC 2000 (Thermo Scientific) equipped with a TR-5MS capillary column $\left(30 \mathrm{~m}^{*} 0.25 \mathrm{~mm} * 0.25 \mu \mathrm{m}\right.$, Thermo Scientific) coupled to a Polaris-Q (Thermo Scientific) ion trap mass spectrometer. Helium was used as carrier gas at a constant flow rate of $1 \mathrm{~mL} \mathrm{~min}^{-1}$ and $1 \mu \mathrm{L}$ of the sample was injected in splitless mode at $280^{\circ} \mathrm{C}$. The $\mathrm{GC}$ oven temperature program was set to start at $65^{\circ} \mathrm{C}$ and ramp to $200^{\circ} \mathrm{C}$ at a $6^{\circ} \mathrm{C} \mathrm{min}{ }^{-1}$ rate and then to $300^{\circ} \mathrm{C}$ at $20^{\circ} \mathrm{C} \mathrm{min}^{-1}$, held for $12 \mathrm{~min}$. The ion source temperature was fixed at $220^{\circ} \mathrm{C}$ and the MS was operated in the electron impact ionization mode $(70 \mathrm{eV})$ in full scan $(\mathrm{m} / z 50-$ $500)$.

\section{Results and discussion}

\subsection{Adaptation of the standard procedure}

\subsubsection{Comparison of ASE and ultrasonic extraction}

The efficiencies of ASE and ultrasonic extraction procedures were compared using identical lichen test samples spiked with levoglucosan-d7 ( $\mathrm{N}=4$ for each procedure). The ASE extraction technique showed satisfying recoveries of $86 \pm 9 \%$, while the results for ultrasonic extraction were below $10 \%$. The ASE also offered interesting preliminary reproducibility results. As expected, decent reproducibility could not be achieved with the low recoveries of ultrasonic extraction. These low recoveries could be explained by the ambient temperature used for ultrasonic extraction, imposed by the low volatility of the dichloromethane extraction solvent, while ASE offers supercritical conditions $\left(100^{\circ} \mathrm{C}\right.$ and 100 bars $)$.

\subsubsection{SPE cleanup}

In order to preserve the GC-MS system from polar compounds such as organic acids, or macromolecules, and to remove a substantial amount of potentially interfering compounds, a cleanup step by SPE was developed. Two SPE sorbents were tested, namely Florisil and silica cartridges. Recoveries were determined for both of them using standard solutions. Hexane and dichloromethane were used as loading and rinsing solvents. Both of them gave satisfying results to load the analytes and to wash the cartridges on both types of solid phase, as no target compounds were detected in the loading and rinsing residuals.

Several solvents were evaluated to eluate the analytes from the SPE cartridges. The recoveries obtained with the Florisil cartridges were all $0 \%$, whatever the solvents tested (acetonitrile, methanol, ethanol or acetone). The results obtained with the silica cartridge are summarized in Table 1, and clearly demonstrated a single possibility to achieve the SPE cleanup, by using silica cartridges and eluting with acetone.

The acetone volume used for the elution step was optimized according to the analyte loading. The experiments were performed with standard solutions, spiked with internal standard. The results, presented in Table 1, are quite homogeneous towards the acetone volume, mannosan presenting slightly lower recoveries $(73-77 \%)$ than the other compounds (83-92\%). However, they were very satisfying for further analytical developments. An assay with a higher amount of analyte loaded was performed to simulate a complex matrix which could potentially saturate the sorbent and interfere with the retention of the analyte. The recoveries reached $94-104 \%$ when increasing monosac- 
LICHEN SAMPLE
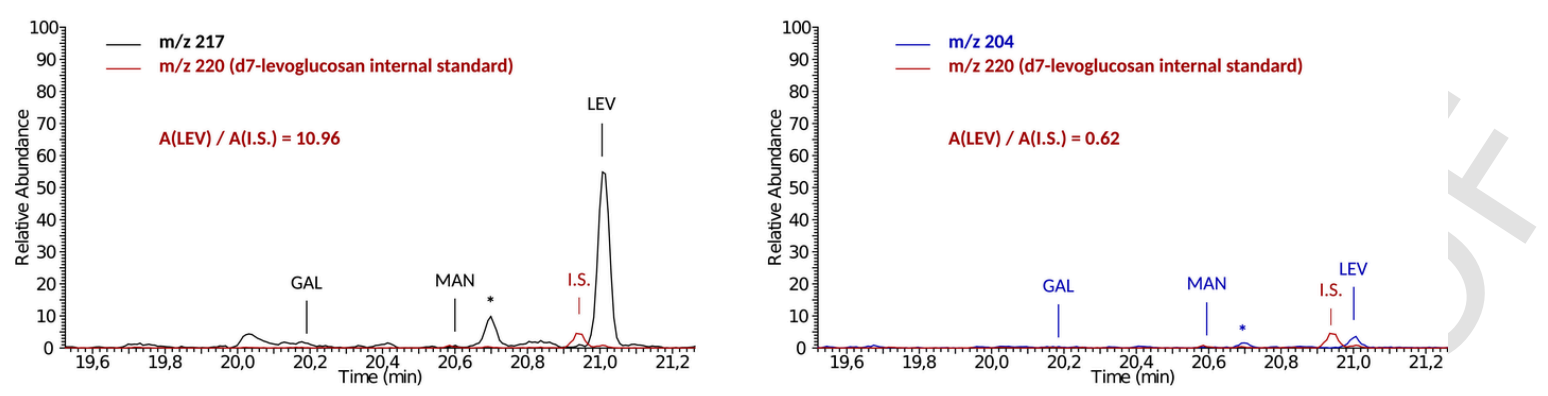

SPIKED LICHEN SAMPLE
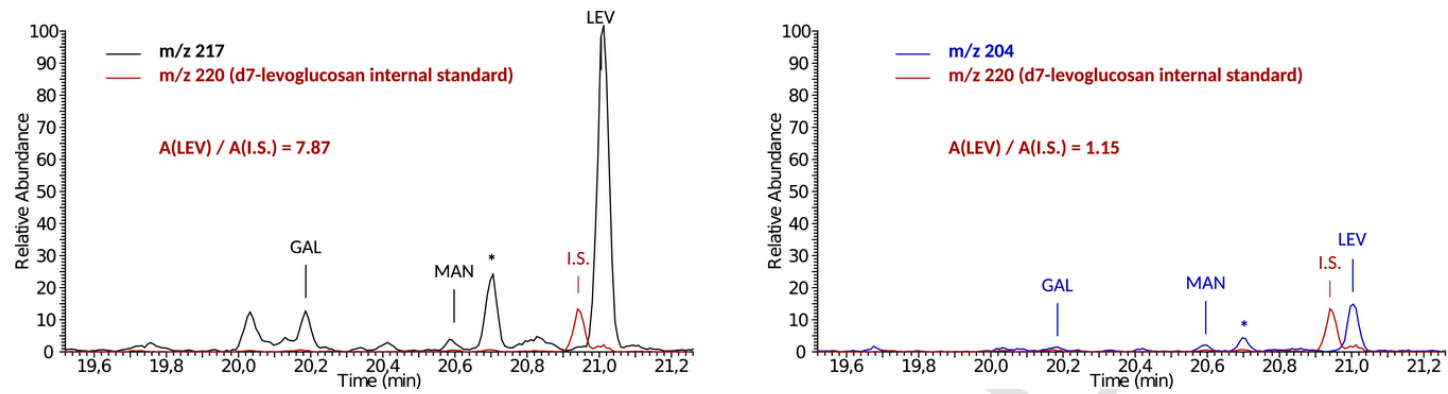

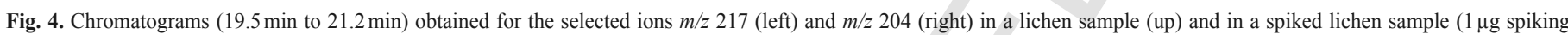

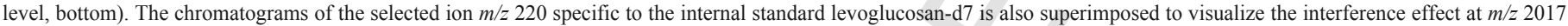
for levoglucosan, and the ratios of levoglucosan/levoglucosan-d7 areas are indicated.* most likely xylulose, from MS spectra interpretation.

charide loading, but at the same time the recovery of levoglucosan-d7, which is aimed to be employed as an internal standard, also raised to $113 \%$. As a greater analyte load implies a greater sample size, and that no significant improvement was obtained considering the internal standard results, an acetone volume of $6 \mathrm{~mL}$ was conserved, according to a standard analyte load of $50 \mu \mathrm{g}$.

\subsubsection{Optimization of silylation derivatization}

The efficiency of the derivatization reaction is critical for the quantitative analysis of monosaccharide anhydrides by GC-MS. In comparison with particulate matter, biological samples may be much more concentrated in monosaccharide anhydrides and in possible interfering compounds i.e. species possessing - $\mathrm{OH}$ chemical groups. This could lead to an incomplete derivatization of the target analytes and an underestimation in monosaccharide anhydrides concentrations. The efficiency of the derivatization can depend on different parameters including reaction time, temperature, derivatization reagent and solvent nature and quantities. Here, the temperature was kept at $70^{\circ} \mathrm{C}$ for all the experiments to favor the silylation reaction, as mentioned by other studies [Medeiros et al., 2006, 5]. The MSTFA reagent was tested but induced the fronting of the chromatographic peaks, even with pyridine as a catalyst, while the results obtained with BSTFA containing $1 \%$ TMCS were very satisfying. This silylation agent was thus conserved for all the further experiments, while the influence of the reaction time, the reagent volume and the addition of pyridine as catalyst was assessed (Fig. 1).

The results showed that the complete derivatization, using the BSTFA $+1 \%$ TMCS as reagent, could only be achieved when combined with pyridine. It was completed for all the compounds under study after only $30 \mathrm{~min}$ of reaction at $70^{\circ} \mathrm{C}$ when pyridine was added (Fig. 1). Shorter times were not tested as the results from previous studies in the laboratory and elsewhere generally required longer reaction times [Medeiros et al., 2006, 5]. Without pyridine, the derivatization yields of monosaccharide anhydrides increased with reaction

time, but never exceeded $70 \%$, even after $180 \mathrm{~min}$. On the other hand, the derivatization yields were not improved by increasing the reagent quantity from 80 to $160 \mu \mathrm{L}$, for any analyte, and only the addition of pyridine achieved a complete reaction, regardless of BSTFA quantity.

The derivatization conditions eventually selected were a reaction time of $90 \mathrm{~min}$, a $80 \mu \mathrm{L}$ volume of BSTFA $1 \%$ TMCS and $80 \mu \mathrm{L}$ pyridine as a catalyzer. From the laboratory experience and the literature mentioned above recommending at least $90 \mathrm{~min}$, this reaction time was adopted for security, even though 30 min were satisfying [Medeiros et al., 2007, 5, 20]. The selected conditions were tested with a spiked lichen test sample and still showed a complete derivatization. The stability of the TMS derivatives at room temperature was verified for $24 \mathrm{~h}$.

\subsubsection{Calibration, reproducibility and detection limits}

The calibration range was determined with standard solutions from 0.2 to $6 \mathrm{mg} \mathrm{L}^{-1}$, with a linearity assessed by correlation coefficients $\left(\mathrm{R}^{2}\right)$ above 0.992, 0.998 and 0.995 (levoglucosan, mannosan and galactosan, respectively) using external calibration. The $\mathrm{R}^{2}$ values were slightly higher when switching to internal calibration, above 0.998, 0.996 and 0.999 (levoglucosan, mannosan and galactosan, respectively), in the same concentration range. The extension of the linearity range was tested down to $0.05 \mathrm{mg} \mathrm{L}^{-1}$ and up to $14 \mathrm{mg} \mathrm{L}^{-1}$, and the $\mathrm{R}^{2}$ results were kept above 0.990 .

The reproducibility experiments were carried out at mid-range $(\mathrm{N}=5)$ and low-range $(\mathrm{N}=6)$ concentrations, and provided very satisfying results, with the $m / z 217$ peak of the TMS derivative. Based on internal calibration, the relative standard deviations (RSD) were below $5 \%$ for the three analytes and were not affected by the concentration levels. The concentrations determined using an internal standard did not suffer from a systematic deviation from the theoretical concentration for levoglucosan $(<3.4 \%)$. The difference from the theoretical concentration was slightly higher for mannosan (7-12\%) and galactosan (17-21\%). Here again, the concentration level did not affect the results. 
These results confirmed the potential of this method, in particular to analyze levoglucosan, which is the main target of this work, as it is the most common biomass burning tracer used worldwide in ambient air samples. Internal calibration was selected for further experiments.

The limits of detection (LOD) and quantification (LOQ) given in Table 2 were calculated from the standard deviation of ten replicates analyzed at $0.25 \mathrm{mg} \mathrm{L}^{-1}$ using the Student's value for a $99 \%$ confidence level.

\subsection{Method validation in the lichen matrix}

\subsubsection{Mass spectra interference from lichen matrix}

The characteristic fragments obtained by GC/MS and electronic impact (EI) ionization of the TMS derivatives were $m / z 217$ (65\% relative abundance), 204 (45\%) and $333(10 \%)$ for levoglucosan and mannosan, 217 (100\% relative abundance) and $204(10 \%)$ for galactosan. Thus, either in the total ion current (TIC) or selected ion (SIM) mode, the compounds under study were easily determined in airborne particulate matter $[5,12,19]$, as well as other inorganic environmental matrices such as sediment and soil [12].

However, fungal and plant tissues are constituted of large amounts of saccharides and sugar alcohols [2, 13, 16, 18], leading to potential matrix effects. Here, it has been demonstrated in several lichen samples that a strong interference occurs for levoglucosan, when scanning the $\mathrm{m} / z 217$ ion. Fig. 2 shows that this artifact is probably due to the co-elution of levoglucosan with a sugar alcohol, as imply the MS peaks at $m / z 307$ and $319[5,12,13]$.

The $m / z 333$ fragment appeared specific to levoglucosan and mannosan, among other saccharides [12], but suffered from a much lower signal intensity compared to $\mathrm{m} / \mathrm{z} 217$ and 204 .

The $m / z 204$ fragment is preeminent in the mass spectra of most saccharides, which are major constituents in algae and bacteria, and a fortiori lichen, but it is absent in the sugar alcohols [12]. From the comparative abundances of $\mathrm{m} / \mathrm{z} 204$ and $\mathrm{m} / \mathrm{z} 333$ observed in the mass spectra of the standard solution and of the lichen sample, no interference was suspected for this ion at the retention time of levoglucosan (Fig. 2), neither for mannosan and galactosan.

\subsubsection{Method validation}

The analysis of spiked lichen samples was achieved to select the best candidate ion for quantification, in particular among interference and sensitivity issues revealed by the study of the mass spectra in lichen matrix, and eventually validate the complete method. These experiments were carried out at 3 spiking levels by adding 1, 2 and $3 \mu \mathrm{g}$ of levoglucosan $(0.25,0.50$, and $0.75 \mu \mathrm{g}$ of galactosan and mannosan) to the finely grounded lichen test sample. The full results are presented in Fig. 3 and the chromatograms displayed for $\mathrm{m} / \mathrm{z} 217$ and $\mathrm{m} / \mathrm{z} 204$ selected ions of the raw lichen sample and the first spiking level are presented in Fig. 4.

For levoglucosan, they confirm the major interference for the $\mathrm{m} /$ $z 217$ ion, as illustrated in Figs. 3 and 4 by the lack of linearity in the ratio of levoglucosan/levoglucosan-d7 areas. As expected, the $\mathrm{m} /$ z 333 fragment intensity is 4 and 5 times lower compared to $\mathrm{m} / z 204$ and 217 , respectively, which could further cause sensitivity issues. Finally, the calculation of concentrations by internal calibration revealed that the levels determined for $m / z 204$ were comparable to what obtained for $m / z$ 333. As the latter is very specific to monosaccharide anhydrides, it corroborated that no interference from the lichen matrix occurred when monitoring $\mathrm{m} / \mathrm{z} 204$. Moreover, $\mathrm{m} / \mathrm{z} 204$ increased linearly with spiking levels, validating this ion for the quantification of levoglucosan.

The response of mannosan and galactosan in the spiked lichen samples was also investigated. Linearity was conserved when working with $\mathrm{m} / \mathrm{z} 204$ instead of the $\mathrm{m} / \mathrm{z} 217$ ion, but it induced a loss of sensitivity for both compounds (Figs. 3 and 4). However, the concentrations deduced from internal calibration were similar whether $\mathrm{m} / \mathrm{z}$ 217 or $\mathrm{m} / \mathrm{z} 204$ was used for quantification, also confirming that mannosan and galactosan did not suffer from coelution interference and could still be quantified with the $m / z 217$ ion.

The overall reproducibility was calculated for the whole extraction and analysis procedure, from the ASE step. The results showed a very high reproducibility, with relative standard deviations $<5 \%(\mathrm{~N}=4)$, indicating that the lichen matrix did not affect the analysis in terms of uncertainty.

\subsection{Analysis of field samples}

Lichen samples were collected from 3 urban background sites in the Marseille metropolitan area and its vicinity (South of France), and analyzed following the developed method. The levoglucosan concentrations were $1.38,0.97$ and $1.06 \mathrm{mg} \mathrm{kg}^{-1}$, in Aix-en-Provence, Marseille and Vitrolles, respectively. On the other hand, neither galactosan nor mannosan were detected. Galactosan and mannosan are generally 1or 2 orders of magnitude below levoglucosan in atmospheric particulate matter samples, which lead logically to undetectable levels in lichens.

The levoglucosan concentrations are higher than PAH measured in lichen collected in nearby urban sites during a previous study, which ranged from 0.25 to $0.65 \mathrm{mg} \mathrm{kg}^{-1}$ [17]. This is consistent with the concentration ratios between levoglucosan and $\mathrm{PAH}$ in the atmospheric compartment usually observed in urban areas $[5,7,9,10]$. Levoglucosan and to a lesser extend $\mathrm{PAH}$ atmospheric concentrations are highly dependent of seasonal variations and local land use, such as the degree of urbanization, and the proximity of industry and agriculture. Also, lichen accumulate over a period of time which may reduce or even eliminate such temporal contrasts, and possibly explain that the difference between PAH and levoglucosan is smaller than what could be possibly expected in winter. On the other hand, the lower level measured in Marseille is consistent with its large and densely urbanized area, where biomass burning from agricultural practices and residential heating is less important than in the Aix-en-Provence city.

\section{Conclusions}

An analytical method has been developed for the determination of monosaccharide anhydrides such as levoglucosan, in lichen samples. Several clean-up conditions were tested and the derivatization conditions were optimized, leading to very satisfying recoveries of the method. The internal standard guarantees the analytical quality of the results in the lichen matrix. The deviation, limit of detection and linearity range suited the expected environmental levels of levoglucosan, which is the most commonly used in atmospheric source apportionment studies.

The application to a lichen test sample showed coelution issues, that were solved by selecting $\mathrm{m} / \mathrm{z} 204$ for quantification. The quality results were as satisfactory as in the standard solution. Finally, lichen samples from urban background sites were analyzed and revealed consistent levoglucosan levels, while galactosan and mannosan were not detected.

The method should be applied to broader sampling campaigns, in order to precise future source apportionment studies using lichen bioindicators, and more globally to investigate the incidence of biomass burning by means of bioindication.

\section{Declaration of Competing Interest}

The authors declare no conflict of interest. 


\section{Aknowledgments}

This work did not receive external funding.

\section{Références}

[1] S. Augusto, C. Máguas, C. Branquinho, Guidelines for biomonitoring persistent organic pollutants (POPs), using lichens and aquatic mosses-a review, Environ. Pollut. 180 (2013) 330-338.

[2] H. Bauer, M. Claeys, R. Vermeylen, E. Schueller, G. Weinke, A. Berger, H Puxbaum, Arabitol and mannitol as tracers for the quantification of airborne fungal spores, Atmos. Environ. 42 (3) (2008) 588-593.

[3] L.K. Boamponsem, C.R. de Freitas, D. Williams, Source apportionment of air pollutants in the Greater Auckland Region of New Zealand using receptor models and elemental levels in the lichen, Parmotrema reticulatum, Atmos. Pollut. Res. 8 (1) (2017) 101-113.

[4] I. El Haddad, N. Marchand, J. Dron, B. Temime-Roussel, E. Quivet, H. Wortham, G. Gille, Comprehensive primary particulate organic characterization of vehicular exhaust emissions in France, Atmos. Environ. 43 (39) (2009) 6190-6198

[5] I. El Haddad, Primary and secondary fractions of the organic aerosol, mMethodologies and application to an mediterranean urban environment, Marseille, Aix-Marseille 1 University, Marseille, France, 2011.

[6] R. Fröhlich, V. Crenn, A. Setyan, A. Belis, F. Canonaco, O. Favez, A. Alastuey, ACTRIS ACSM intercomparison-Part 2: intercomparison of ME-2 organic source apportionment results from 15 individual, co-located aerosol mass spectrometers, Atmos. Meas. Tech. 8 (6) (2014) 2555-2576.

[7] M. Giannoni, T. Martellini, M. Del Bubba, A. Gambaro, R. Zangrando, M. Chiari, A. Cincinelli, The use of levoglucosan for tracing biomass burning in PM2. 5 samples in Tuscany (Italy, Environ. Pollut. 167 (2012) 7-15.

[8] E.C. Hopmans, R.A.L. dos Santos, A. Mets, J.S.S. Damsté, S. Schouten, A novel method for the rapid analysis of levoglucosan in soils and sediments, Org. Geochem. 58 (2013) 86-88.

[9] A. Jedynska, G. Hoek, M. Eeftens, J. Cyrys, M. Keuken, C Ampe, K. de Hoogh, Spatial variations of $\mathrm{PAH}$, hopanes/steranes and $\mathrm{EC} / \mathrm{OC}$ concentrations within and between European study areas, Atmos. Environ. 87 (2014) 239-248.

[10] A. Jedynska, G. Hoek, M. Wang, M. Eeftens, J. Cyrys, R. Beelen, W. Nystad, Spatial variations of levoglucosan in four European study areas, Sci. Total Environ. 505 (2015) 1072-1081.
[11] C. Lai, Y. Liu, J. Ma, Q. Ma, H. He, Degradation kinetics of levoglucosan initiated by hydroxyl radical under different environmental conditions, Atmos. Environ. 91 (2014) 32-39.

[12] P.M. Medeiros, B.R. Simoneit, Analysis of sugars in environmental samples by gas chromatography-mass spectrometry, J. Chromatogr. A 1141 (2) (2007) $271-278$.

[13] G.D. Mogoşanu, A.M. Grumezescu, D.E. Mihaiescu, D. Istrati, D.E. Mogoşanu, S.A. Buteica, Identification of sugars from Silene albae herba using GC-MS technique, UPB Sci. Bull. Ser. B 73 (2011) 101-108.

[14] P.L. Nimis, C. Scheidegger, P.A. Wolseley, Monitoring With Lichens - Monitoring Lichens, Springer, Dordrecht, 2002.

[15] C. Piot, J.L. Jaffrezo, J. Cozic, N. Pissot, I. El Haddad, Marchand, N., J.L. Besombes, Quantification of levoglucosan and its isomers by high performance liquid chromatography-electrospray ionization tandem mass spectrometry and its application to atmospheric and soil samples, Atmos. Meas. Tech. 5 (2012) 141-148.

[16] M. Raessler, Sample preparation and current applications of liquid chromatography for the determination of non-structural carbohydrates in plants, TrAC Trends Anal. Chem. 30 (11) (2011) 1833-1843.

[17] A. Ratier, J. Dron, G. Revenko, A. Austruy, C.E. Dauphin, F. Chaspoul, E. Wafo, Characterization of atmospheric emission sources in lichen from metal and organic contaminant patterns, Environ. Sci. Pollut. Res. 25 (9) (2018) 8364-8376.

[18] M.L. Sanz, I. Martínez-Castro, Recent developments in sample preparation for chromatographic analysis of carbohydrates, J. Chromatogr. A 1153 (1-2) (2007) 74-89.

[19] B.R. Simoneit, J.J. Schauer, C.G. Nolte, D.R. Oros, V.O. Elias, M.P. Fraser, G.R. Cass, Levoglucosan, a tracer for cellulose in biomass burning and atmospheric particles, Atmos. Environ. 33 (2) (1999) 173-182.

[20] A. Sylvestre, Characterization of industrial aerosols and quantification of its contribution in atmospheric PM2.5 (Doctoral dissertation, Aix-Marseille University, Marseille, France, 2016.

[21] C. You, T. Yao, S. Gao, P. Gong, H. Zhao, Simultaneous determination of levoglucosan, mannosan and galactosan at trace levels in snow samples by gc/ms, Chromatographia 77 (13-14) (2014) 969-974.

[22] K.E. Yttri, C. Dye, L.H. Slørdal, O.A. Braathen, Quantification of monosaccharide anhydrides by liquid chromatography combined with mass spectrometry: application to aerosol samples from an urban and a suburban site influenced by small-scale wood burning, J. Air Waste Manage. Assoc. 55 (8) (2005) 1169-1177. 